\section{THE GASEOUS, LIQUID, AND SOLID STATES OF WATER-SUBSTANCE *}

$\mathrm{N}$ two communications made by me to the British Association 1 at its meetings at Edinburgh in 1871 , and at Brighton in 1872 , and printed as abstracts in the Transactions of the Sections for those years, considerations were adduced on relations between the gaseous, the liquid, and the solid states of matter. The new subject of the present paper constitutes a further development of some of those previous considerations, and a brief sketch of these is necessary here as an introduction for rendering intelligible what is to follow.

Taking into consideration any substance which we can have in the three states, gaseous, liquid, and solid, we may observe that when any two of these states are present in contact together, the pressure and temperature are dependent each on the other, so that when one is given the other is fixed. Then if we denote geometrically all possible points of temperature and pressure jointly by points spread continuously in a plane surface, each point in the plane being referred to two axes of rectangular coordinates, so that one of its ordinates shall represent the temperature and the other the pressure denoted by that point, we may notice that there will be three curves, one expressing the relation between temperature and pressure for gas with liquid, another expressing that for gas with solid, and another expressing that for liquid with solid. These three curves, it appears, must all meet or cross each other in one point of pressure and temperature jointly, which may be called the triple-point. The triple-point, considered in respect to its temperature, is in fact what would often be cailed the freezing point in vacuso; that is, the freezing temperature of water in contact with no gas except its own aqueous vapour or steam; and the pressure at the triple point is just the pressure of that aqueous gas or steam.

The curve between gas and liquid, which may be called the boilino-line, will be a separating boundary between the regions of the plane corresponding to the ordinary liquid and those corresponding to the ordinary gaseous state. But by consideration of Dr. Andrews's experimental results ("Phil. Trans.," I869) we may see that this separating boundary comes to an end at a point of temperature and pressure which, in conformity with his language, may be called the critical point of pressure and temperature jointly; and we may see that, from any liquid state to any gaseous state, the transition may be gradually effected by an infinite variety of courses passing round the extreme end of the boiling-line.

The accompanying figure serves to illustrate these considerations in reference to transitions between the three states, the gaseous, the liquid, and the solid. The figure is intended only as a sketch to illustrate principles, and is not drawn according to measurements for any particular substance, though the main features of the curves shown in it are meant to relate in a general way to the substance of water, steam, and ice. A X and $\mathrm{A} \mathrm{Y}$ are the axes of coordinates for the temperatures and pressures respectively; $A$, the origin, being taken as the zero for pressures and as the zero for temperatures on the Centigrade scale. The curve $\mathrm{L}$ represents the boiling-line terminating in the critical point $\mathrm{E}$. The line $\mathrm{T} \mathrm{M}$ represents the line between liquid and solid. It is drawn showing in an exaggerated degree the lowering of the freezing temperature of water by pressure; the exaggeration being necessary to allow small changes of temperature to be perceptible in the diagram. The line $\mathrm{T} \mathrm{N}$ represents the line between the gaseous and the solid states of water-substance. The line L T N appears to have been generally (in the discussion of experimental results on the pressure of aqueous vapour above and below the freezing-point) regarded as one continuous curve; but it was part of my object in the two British-Association papers referred to, to show that it ought to be considered as two distinct curves ( $\mathrm{L} T \mathrm{P}$ and $\mathrm{N} \mathrm{T} \mathrm{Q}$ ) crossing each other in the triple-point $\mathrm{T}$.

In the second of the two British-Association papers already referrad to (the one read at the Brighton meeting, 1872), I gave demonstrations showing that these two curves $\mathrm{L} T$ and $\mathrm{N} T$ should meet, as shown in the accompanying figure, with a re. entrant angle at $\mathrm{T}$, not with a salient angle such as is exemplified in the vertex of a pointed arch; and offered in conclusion the suggestion that the reasoning which had been adduced

* "A Quantitative Investigation of certain Relations between the Gaseous, the Liquid, and the Solid States of Water-Sizbstance." By Prof. James the Liquid, and the Solid States of Water-Sirbstance." By Prof, James LL.D., F.R.S. Abridged for NATURE by the Author. might be followed up by a quantitative calculation founded on experimental data, by which calculation the difference of the pressures of steam with water, and steam with ice for any given temperature very near the triple point, may be found with a very close approximation to the truth.

In the month of October 1872 I explained to my brother, Sir William Thomson, the nature of that contemplated quantitative calculation: I mentioned to him the method which I had prepared for carrying out the intended investigation, and inquired of him for some of the experimental data, or data already deduced by theory from experiments, which I was seeking to obtain. On his attention being thus turned to the matter, he noticed that the desired quantitative relation could be obtained very directly and easily from a simple formula which he had given in his paper on the Dynamical Theory of Heat, "Transactions of the Royal Society of Edinburgh," March 17, 1851, $\$ 2$ I (3), to express the second law of thermodynamics for a body of uniform temperature throughout, exposed to pressure equal in all directions.

That formula is

$$
\frac{d p}{d t}=\mathrm{CM}
$$

in which $p$ denotes the amount of the pressure, and $\frac{d p}{d t}$ its rate of increase per unit increase of temperature, the volume being kept constant; $\mathrm{C}$ denotes Carnot's function; and $\mathrm{M}$ denotes the rate of absorption at which heat mast be supplied to

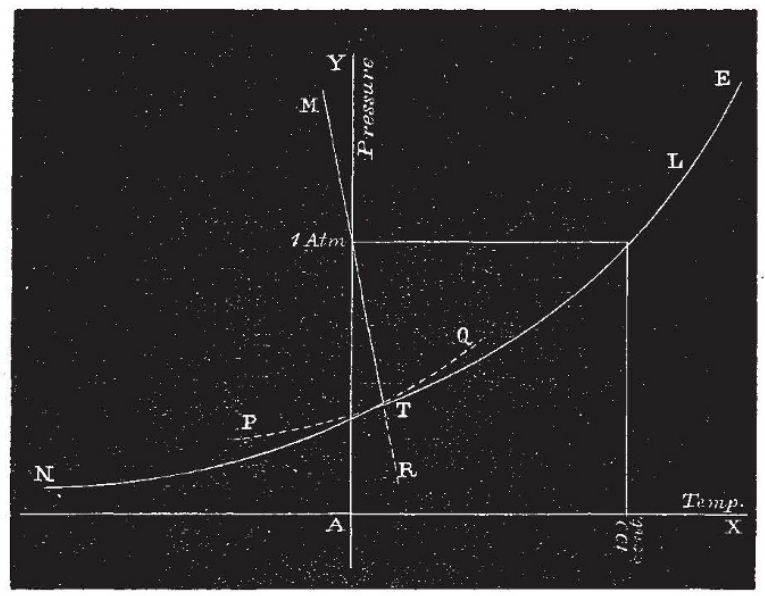

the substance per unit augnentation of volume, to let it expand without varying in temperature. The body may be either homogeneous throughout, as a continuous solid, or liquid, or gas ; or it may be heterogeneous, as a mass of water and aqueous vapour (i.e. steam), or ice and water, or ice and aqueous vapour (i.e. steam).

Now apply that formula, Ist, to steam with water, and 2nd, to steam with ice, the temperature of the heterogeneous body in each case being that of the triple-point, or we may for the present purpose say $0^{\circ} \mathrm{C}$., which is almost exactly the same. It is to be observed that while in the general application of the formula the rate of increase of the pressure with increase of tem. perature, when the crolume is kept constant, has been denoted by $\frac{d p}{d t}$, yet in each of the two particular cases now brought under consideration it is a matter of indifference whether the volume be kept constant or not ; because the pressure of steam in con. tact either with water or with ice, for any given temperature, is independent of the volume of the whole heterogeneous body ; so that the change of pressure for change of temperature is inde. pendent of whether there be change of volume or not. As C is a function of the temperature which has the same value for all substances at the same temperature, it has the same value for the two cases now under consideration. Hence, retaining for the first case (that, namely, of steam with water) the same notation as before, but modifying it by the use of an accent where distinction is necessary in the second ease (that of steam with ice), and thus using $\frac{d p}{d t}$ to denote the rate of increase of the pressure per unit increase of temperature for steam with wate 
at the triple-point $\left(0^{\circ} \mathrm{C}\right.$. nearly), and $\mathrm{M}$ to denote the rate of absorption at which heat must be supplied to a body consisting of steam and water at the triple point, per unit augmentation of volume of that whole heterogeneous body, to let it expand without varying in temperature, and using $\frac{d p^{\prime}}{d t}$ and $M^{\prime}$ to denote the corresponding rates for steam with ice at the triple point, we have

$$
\frac{\frac{d p}{d t}}{\frac{d p^{\prime}}{d t}}=\frac{\mathbf{M}}{\mathbf{M}^{\prime}}
$$

The latent heat of evaporation of one pound of water at the freezing-point (or at the triple point) into steam at the same temperature, as determined by Regnault, is 606.5 thermic units, the thermic unit being here taken as the heat which would raise the temperature of $\mathrm{I}$ lb. of water $\mathrm{I}^{\circ} \mathrm{C}$., and the latent heat of fusion of ice is about 78 or 79 of the same thermic units. Hence, though $\mathrm{M}$ and $\mathrm{M}^{\prime}$ belong each to a cubic foot of steam at the triple point, not to a pound mass of it, still the ratio $\frac{\mathrm{M}}{\mathrm{M}^{\prime}}$ is $=$ 606

$79+606$

Hence

$$
\frac{\frac{d p}{d t}}{\frac{d p}{d t}}=\frac{606}{79+606}=\frac{1}{I \cdot I 3}
$$

This shows that for any small descent in temperature from the triple point (where the pressure of steam with ice is the same as that of steam with water), the pressure of steam with ice falls off $I_{1} \cdot 3$ times as much as does the pressure of steam with water.

In submitting the quantitative calculation now given, I have preferred to adopt the method proposed and developed by my brother rather than that which I had myself previously devised, because his method is simpler, and brings out the results more briefly by established principles from existing experimental data. I may say, however, that the method devised by myself was also a true method, and that I have since worked it out to its numerical results, and have found that these are quite in accordance with those brought out by my brother. The two indeed may be regarded as being essentially of the same nature; and I think it unnecessary to occupy space by giving any details of the method I planned and have carried out. Its general character may be sufficiently gathered from the concluding passages of the British Association 1872 paper, as printed in the Transactions of the Sections, Brighton Meeting.

In order to discover whether the feature now developed by theoretical considerations is to be found showing itself in any degree in the experimental results of Regnault on the pressures of steam at different temperatures *, I have made careful examinations of his engraved curve (Plate viii. of his Memoir), and his empirical formulæ adapted to fit very closely to the results exhibited in that curve, and of his final tables of results at the close of his Memoir; and by every mode of scrutiny which I have brought to bear on the subject-in fact by each of some seven or eight varied modes-I have met with clear indication of the existence of the expected feature ; and by some of them I havefound that it can readily be brought prominently into notice. The engraved curve drawn on the copperplate by Regnault himself is offered by him as the definitive expression of his experiments, as being an expression which satisfies as well as possible the aggregate of his observations ; subject, however, to a very slight alteration, which he has pointed out as a requisite amendment in the part of the curve immediately below the freezing*point, a part with which the investigations in the present paper are specially concerned.

Aftertelling (p. 581 of his Memoir) of the great care with which he had marked the curve on the copperplate and got it engraved, he says:- "Je n'ai pas pu éviter cependant quelques petites irrégularités dans les courbes; mais une seule de ces irrégularités me paraît assez importante pour devoir être signalée. Elle se présente pour les basses températures comprises entre $0^{\circ}$ et $-16^{\circ}$, la courbe creuse trop vers l'axe des températures, elle laisse, notablement creus d'elle, toutes les déterminations expérimentales qui ont été faites entre $0^{\circ}$ et $-10^{\circ}$. Ainsi les valeurs, que cette

* Regnault. “Des forces elastiques de la vapeur d'eau aux différentes températures," Mémoires de l'A.cadémie des Sciences, 1847. petite portion de la courbe donne pour les forces élastiques, sont un peu trop faibles, et j'ai eu soin de les augmenter, de la quantité convenable, dans les nombres que je donnerai plus loin." Whether we are now to think that this bend downwards ${ }^{*}$ of the curve towards the axis of temperatures involving what Regnault regarded as a small faulty departure of his drawn curve from his actual experiments, was introduced merely by a casual want of accuracy in drawing, or whether we may suppose that possibly there may have been some experimental observations which attracted the curve downwards, but were afterwards rejected on a supposition of their being untrustworthy, it appears that such a bend is a feature which the curve really ought to possess, and is one which, even after being partially smoothed off by way of correction, is not obliterated, but still remains clearly discoverable in the final numerical tables of results.

This is best brought to light by means of the empirical formulæ devised and employed by Regnault for the collating of his results. He proceeded evidently under the idea of the curve being continuous in its nature, so that a single formula might represent the pressures of aqueous vapour throughout the whole of his experiments; but before seeking for such a formula he proceeded to calculate several local formulæ of which each should represent very exactly his experiments between limits of temperature not wide apart; and afterwards he worked out several general formulæ, each adapted singly for the whole range of his experiments.

Now in the paper communicated to the Royal Society, and printed in the Proceedings for December II, 1873, from which the present paper is an abridgment, the details of a scrutiny of the chief of these formulæ are given (the formulæ, especially, which were adopted by Regnault for deducing his final general table extending from $-32^{\circ} \mathrm{C}$. to $+230^{\circ} \mathrm{C}$.), from which it appears that they present clear indications that at and very close to the freezing-point (or rather the triple-point) the rate of increase of pressure for increase of temperature is decidedly less in the case of steam with water than in that of steam with ice; or, in other words, that at and very close to the triple-point the steepness of the curve for steam with water is decidedly less than that of the curve for steam with ice; or, to state the same a little more fully, that while the steepness is increasing as we ascend from temperatures below the triple-point up to the triple-point, with ice in contact with steam, there is a sudden abatement of the steepness in passing the triple-point, where the change occurs from steam with ice to steam with water, after which, with continued rise of temperature, the steepness goes on again increasing. In fact the result comes out that these formulæ, expressing an aggregate of experimental results of Regnault, would indicate dp

for $\frac{\overline{d t}}{d p^{\prime}}$ at the freezing-point, or the triple-point, not the value I $\frac{1}{d t}$

(as would be the case if a curve continuous past the triple-point would express the pressure of steam or aqueous vapour, for different temperatures, in contact with ice below the triple-point and with water above it), but $r^{\circ} 09$ or $1 \cdot 10$, which makes a near approach to the result I'I3 found by my brother's quantitative calculation already here cited. The decimal fractions in excess of unity, here represent the quantitative relation between the greatness of the feature under consideration as brought out by the theoretical investigation on the one hand, and as deduced from Regnault's results on the other hand : and thus we may say that this feature can be brought to view as existing in Regnault's principal results in a degree about $\frac{9}{13}$ or $\frac{10}{1} \frac{0}{8}$ of that in which the theoretical investigation shows that it must really exist, and ought to be found experimentally, if the experiments had a sufficiently minute exactitude to detect it and to measure it.

Regnault also gives, in the same Memoir, another statement of results deduced from his experiments, and put in the form of a table intended chiefly for meteorological purposes; which table shows the pressures of aqueous vapour for temperatures ranging below and above the freezing-point at very small intervals of temperature, $\frac{1}{1^{1}}$ th of a degree centigrade each. In this table, the numbers inserted as representing the pressures below the freezing-point are slightly different from the corresponding ones in his general table, which, with the formulæ used in making it, has just now been referred to; and he mentions that this slight

* In M. Regnault's curve the temperatures are measured horizontally across the sheet and pressures are measured upwards. 
discrepance has resulted from the fact that the two tables were formed at different periods, and were not calculated by the same formula; but he remarks that the differences are insignificant, as they scarcely amount to $\mathrm{O} 2$ millimetre of mercury in the pressures which the two tables respectively show. Here, too, as in the general table, the feature expected shows itself, though in a diminished degree. By careful examination of the minute changes of pressure for small changes of temperature, close to the freezing-point, both above and below it, as they are shown in this table, $\mathrm{I}$ find that the experimental results as here offered would indicate the existence of the feature in a degree about $\frac{5}{13}$ or $\frac{6}{13}$ of that in which the theoretical investigation now shows that it ought to be met with, if experiments could be made on pressures of aqueous vapour, above and below the freezing-point, with sufficiently minute exactitude.

It is indeed a great credit to the accuracy of Regnault's experiments, and to the exactitude of his results, that the results contain the clear indications they do of this feature, which only comes to view through comparison of differences of pressure represented by very minute fractions of a millimetre of mercury; and which, unless a very high order of accuracy were maintained, might have given no perceptible indication of its existence, or might readily have been made to disappear totally from the final results, through the application of the ordinary methods for clearing off small errors of observation.

\section{SCIENTIFIC SERIALS}

American Fournal of Science and Arts, February 1874,-This number commences with a paper by Mr. Langley (accompanied with plate), describing studies on the minute structure of the solar photosphere, made at the Alleghany Observatory. The equatorial used had an aperture of 13 inches. The author finds that the ultimate visible constituents of the photosphere are not the "rice grains," but small gramules composing them, and not more than $\mathrm{O}^{\prime \prime} \cdot 3$ in size. Comparing the total area covered by them with that of the whole sun, he estimates that the greater fart of the solar light comes from an area of not over one-ifth of its visible surface, and which may be indefinitely less. Hence the received estimates of the intensity of the action to which solar light is due must, he thinks, be greatly increased. In the penumbra there are not only numerous small cyclones, and even right- and left-handed whirls in the same spot, but probably currents ascending nearly vertically. The action of superposed approximately horizontal currents is a prominent feature. The outer penumbral edge seems to be formed by rupture. Mr. Langley accepts M. Faye's theory as the most probable.-Prof. Pickering communicates some measurements of the polarisation of light reflected by the sky, and by one or more plates of glass. One remarkable result arrived at was, that the polarisation (from the sky) is the same, for a given solar distance, for any meridian distance ; in other words, that the polarisation is the same for all points equally distant from the sun.-In a translated paper on the dissipation of electricity in gases, by a Russian physicist, M. Boboulieff, the author concludes from his experiments, that the dissipation in air (and other gases) diminishes with diminution of the pressure; and that the dissipation in hydrogen is less than in air (at the same pressure).-Mr. Verrill continues his notes on results of recent dredging expeditions on the coast of New England. - In the "Scientific Intelligence" we find a summary of a recent important memoir by Prof. Morse on the systematic position of the Brachiopoda. His avowed object is to show that in every point of their structure the Brachiopoda are true worms, with possibly some affinities to the Crustacea, and that they have no relations to the Mollusca, save what many other worms may possess in common with them.--The organisation of an American Metrological Society is announced; the design being to originate and promote measures for improving the system of weights, measures, and moneys, and bring these into relations of simple commensurability with each other.

In the number of the Bulletin Mensuel de la Societté 'Acclimatation de Paris issued in January one of the principal papers is an article by $M$. Mérice on Agriculture in Brazil. This country is by nature fitted to be one of the most prolific agricultural tracts of earth in the world, so varied and abundant are its productions, and so fruitful its soil. Improved implements are necessary, and increased skill would give greatly increased results. Great strides are being taken in the" "education" of various kinds of silkworms, and under the directions given in the
Bulletin the different varieties may be properly reared on the most approved principles. - M. Carbonnier, to whom the honour is due of introducing the "Paradise fish" from China, has been successful in importing some live specimens of another species of Macropodus, the "rainbow-fish" of India: specinoens of the Pesca-re, or "king-fish" of South America have also been brought to Paris from Buenos Ayres. M. E. Perris' paper on birds and insects is continued.-The recent transmission of salmon ova to New Zealand, the cultivation of lobsters in the United States, the introduction of the Eucalyptus in various parts of Europe, are all, amid a mass of other matter, referred to at length. The number for January, just received, gives an interesting account of the year's work at the fardin d'Acclimatation. In the Bois de Boulogne experiments have been made in the cultivation of various vegetables and other useful plants, on the results of which the future utilisation of new importations greatly depends. - The notes on the cultivation of the vine and on the use of mineral manures will be found very valuable. $\rightarrow$ The question of fish culture, which has assumed such large proportions in England and America, is being taken up by the Society, and an interesting paper on the subject is contributed by $M$. de la Blancheu.

Reale Istituto Lombardo di Scienze e Letlers. Rendiconti Dec. 18, 173. In this number Prof. Lombroso furnishes exact measurements of the crania of 66 Italian criminals (from various musetum collections) along with an interesting analysis of those data. With reference to capacity as measured by apparent circumference, while there were a few of pretty large circumference ( 1 of 580,1 of 550,2 of 560,2 of 540 , out of 65 ), and a moderate number of ordinary size ( 8 of 530,13 of 520 ), a large proportion were quasi-microcephalic (39 out of 65 ) ; and precisely 19 of $5 \mathrm{IO}, 8$ of 490 , and 12 of 500 . Of 40 crania examined the mean capacity, in cubic centimetres, was 1,389 ; two were of more than ordinary capacity $(\mathrm{r}, 6 \mathrm{ro}$ and $\mathrm{I}, 633), 3$ were of ordinary ( $I, 500$ and more), $I 2$ had a capacity of $I, 400$ and more, I9 were of much inferior capacity $(\mathrm{r}, 300$ and more), while 4 were truly microcephalic, with a capacity of 1,100 to 1,200 . Of the last, 2 were crania of assassins, I that of a thief, and $r$ that of an incendiary (with intent to rob). Prof. Cantoni gives the concluding portion of a valuable paper in experimental physics, on the polarisatiin of non-conductors. He here takes up several objections urged by Prof. Righi to his opinion as to the possibility of polarising a non-conductor durably.- M. Corradi continues an historical sketch of the study and teaching of anatomy in Italy in the Middle Ages.-We also note short papers on primitive tumours of the dura mater (by M. Bizzozero), and on a remarkable appearance of the zodiacal light, and a shower of falling stars observed in some parts of Italy on December 12 last.

Bulletin de l'Academie Royale des Sciences (de Belgique). No. 12. In this number are given a series of papers or lectures of a somewhat popular nature, read at the public seance in December. The first is by M. Gluge, who arvocates the teaching of biology in the Belgian schools. - M. d'Omalius d'Halloy follows with arı argument for the hypothesis of transformation by generations of forms from a first creation, as against that of successive creations on the one hand, and that of evolution from matter on the other. - The next lecture, by M. van Beneden, is entitled "A Word on the Social Life of the Inferior Animals," and gives some curious facts in natural history, relating especially to parasites. -And lastly, we have an able lecture by M. Schwann, on the commencement and the end of the world, according to the mechanical theory of heat. The author gives a lucid exposition of the two fundamental principles of conservation and dissipation of energy, explaining, with special fulness, the doctrine enunciated by Clausius and the considerations leading to it.-The Bulletin further contains reports by members of the Academy on various prize-competitions. One subject proposed was the relation of heat to development of phanerogamic plants, with special reference to the periodic phenomena of vegetation. The Committee give lengthy analyses of the memoir received, to which, while of some scientific merit, the prize is not awarded. In a lecture by M. Morreu on the subject, the law is elucidated, that, other things being equal, the quartity of carbon fixed by a vegetation is greater in proportion as its height is less, inasmuch as this supposes a less expenditure of movement.- Another question called for a description of the coal system of the Liége Valley. From a memoir on which the committee report favourabiy, it appears that instead of having twenty-five beds of coal, as had been thought since the labours 